DOI: https://doi.org/10.24867/02EF11Cancarevic

\title{
PRIMENA TEHNOLOGIJE PROŠIRENE REALNOSTI U OBUCI OPERATERA GRAFIČKOG SISTEMA PERFECTA 76
}

\section{USAGE OF AUGMENTED REALITY TECHNOLOGY IN TRAINING OF PERFECTA 76 GRAPHIC SYSTEM OPERATOR}

\begin{abstract}
Sara Čančarević, Gojko Vladić, Stefan Đurđević, Fakultet tehničkih nauka, Novi Sad
\section{Oblast - GRAFIČKO INŽENJERSTVO I DIZAJN}

Kratak sadržaj - Rad obuhvata teorijske osnove proširene realnosti, poređenje sa virtuelnom realnošću, hardverske $i$ softverske komponente kao i primenu proširene realnosti sa akcentom na njenu primenu u edukaciji. Kao rezultat rada kreirana je aplikacija proširene realnosti za obuku opera-

\section{PROŠIRENA REALNOST}

Proširena stvarnost (engl. Augmented Reality- AR) predstavlja stvaran (realan) svet proširen kompjuterski generisanim podacima i objektima. Kompjuterski generisan sadržaj može biti u obliku slika, audio i video zapisa, 3D modela i slično.
\end{abstract} tera grafičkog sistema Perfecta 76. Praktični deo obuhvata idejno rešenje i proces izrade aplikacije u Unity sofverskom okruženju i Vuforia dodatku za AR.

Ključne reči: Proširena realnost, AR, edukacija, aplikacija, android platforma, Unity, Vuforia

Abstract - This paper contains basic theory of augmented reality, comparison with virtual reality, hardware and software components and usage of augmented reality with accent on educational usage. Result of this work is application which is used to train Perfecta 76 graphic system operator. Practical part include conceptual solution and application making process in Unity and his extension for augmented reality Vuforia.

Keywords: Augmented reality, AR, education, application, android platform, Unity, Vuforia

\section{UVOD}

Prvi sistem prikaza slika proširene i virtuelne realnosti uređajem montiranim na glavu korisnika (engl. Head-Mounted Display- HMD) razvio je 1968. godine Ivan Saterland sa svojim studentom Bobom Sproulom. Sistem je radio na bazi CRT tehnologije i bio je primitivan u pogledu interfejsa i realnog prikaza, dok je grafika prikazivala konture trodimenzionalnog objekta. Model je dobio naziv , Mač Damoklea" (engl. The Sword of Damocles) zbog svoje masivne konstrukcije koja se spuštala sa plafona do glave korisnika [1]. Iako mogućnosti tehnologije nisu bile poput današnjih, sam koncept je izazvao veliku zainteresovanost. Termin „Proširena realnost” pominje se početkom devedesetih godina prošlog veka, od strane Kaudela i Majzela, naučnika Boing korporacije, koji su razvili jedinstven AR sistem koji omogućava radnicima lakše spajanje žica [2].

U narednim godinama, proširena realnost je postala dosta popularnija i korišćena je u različitim tehnologijama, a sa razvojem tehnologije mobilnih telefona, razvijala se i tehnologija proširene realnosti.

\section{NAPOMENA:}

Ovaj rad proistekao je iz master rada čiji mentor je bio dr Gojko Vladić, docent.
Prema Azumi [3], AR sistemi se zasnivaju na tri osnovna koncepta:

1. kombinovanje virtuelne grafike sa realnim svetom

2. interaktivnost $u$ realnom vremenu

3. 3D registracija digitalnih podataka.

Razlika između augmentovane i virtualne realnosti (engl. Virtual Reality- VR) ogleda se u tome da VR daje veštački generisano okruženje, odnosno re-kreiranje potpuno novog okruženja, dok AR ne pokušava da zameni realno okruženje veštački generisanim, dakle korisnici i dalje imaju interakciju sa realnim okruženjem, ali istovremeno im se nudi dodatni sadržaj koji nadograđuje informacije o realnom okruženju [4]. S obzirom da često ne postoji jasna granica između realnog i virtuelnog sveta, Pol Milgram je 1994. godine predstavio koncept „Proširene virtualnosti” (engl. Augmented Virtuality- AV) koja predstavlja oblast nejasnih granica gde su udružene AR i VR tehnologije. Danas se ova oblast naziva Mešovitom realnosti (engl. Mixed Reality- MR). Mešovita realnost (Slika 1) je rezultat mešanja fizičkog sveta sa digitalnim svetom, i te dve realnosti daju krajeve spektra zvanog Virtuality Continuum [5].

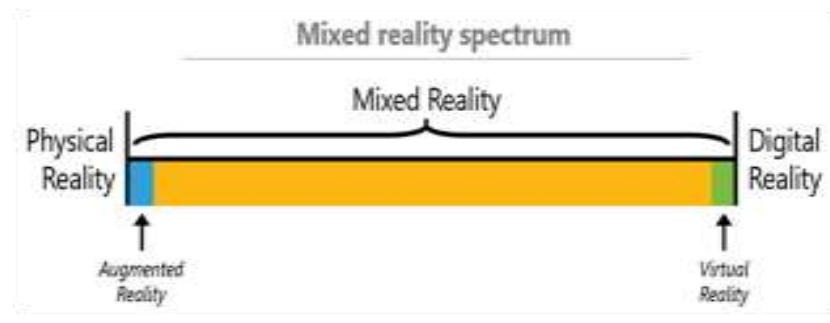

Slika 1. Mešovita realnost

\subsection{Hardverske komponente proširene realnosti}

U hardverske komponente spadaju procesor, ekran, ulazni uređaji (kamera) i senzori. Moderni pametni telefoni i tableti sadrže sve potrebne elemente (procesor, ekran, kameru), kao i MEMS senzore kao što su akcelerometar i GPS. Najveća prepreka za rasprostranjenost AR aplikacija 
je nedostatak adekvatnog hardvera, shodno tome input kamere i algoritmi za prepoznavanje i praćenje objekta oduzimaju značajan deo procesorskog vremena, pa se mora voditi računa o kompleksnosti digitalnog sadržaja koji treba da se nadogradi preko slike. AR je, takođe, limitiran veličinom mobilnog uređaja ili statičkog monitora. Rešenje ovog problema je razvoj AR HMD [4].

Postoje dve vrste HMD-a:

- HMD koji prikazuje samo kompjuterski generisane slike ova vrsta HMD-a se ne koristi za AR aplikacije.

- HMD koji omogućava nadograđivanje realnog sveta sa kompjuterski generisanim slikama [6].

\subsection{Softverska komponenta proširene realnosti}

Ključni uspeh AR aplikacija je u tome koliko će realistično integrisati nadograđene elemente u postojeće okruženje. Softver treba da pronađe objekte koji služe kao markeri i ustanovi njihovu poziciju u prostoru. Ovaj proces naziva se registracija slike i za njega su potrebne različite metode mašinskog viđenja za prepoznavanje i praćenje objekata [4].

\section{Registracija slike se obično sastoji iz dve faze:}

1. Detekcija interesnih tačaka i markera na slici - koriste se metode detekcije svojstva slike poput detekcije uglova, ivica i neravnina, prag osetljivosti (engl. Treshhold) i druge metode obrade slike.

2. Određivanje pozicije markera iz podataka dobijenih u prvoj fazi (koristi se geometrija) [4].

Aplikacija proširene realnosti radi na način da se kamerom HMD uređaja ili mobilnog telefona snima realno okruženje, ta video slika se transformiše i utvrđuje se položaj markera (koji je prethodno zadat u kodu pri kreiranju aplikacije). Zatim, algoritam određuje orijentaciju i izračunava stvarnu poziciju digitalne kamere $\mathrm{u}$ odnosu na fizički marker. Nakon što je marker prepoznat, vrši se pozicioniranje nadograđenih digitalnih objekata i njihovo renderovanje u kadar video zapisa [7].

Potražnja za kvalitetnim iskustvom proširene realnosti sve više raste. Programeri koji žele da kreiraju AR aplikaciju imaju veliki izbor softverskih alata za izradu AR aplikacije. Neke od kompanija koje omogućavaju softverskih alate za AR su: ARToolKit, Wikitude, Kudan, Augmenta, EaszAR, Metaio, Blippar (udružen sa Layar) Unity i mnoge druge.

\subsection{Primena proširene realnosti u edukaciji}

Tokom godina, pojava novih tehnologija omogućava i nove mogućnosti u obrazovanju. Na primer, decenije istraživanja pokazale su da učionice koje su opremljene računarskom tehnologijom, u poređenju sa onim koje nisu, mogu obogatiti predavanja i učenje, i time povećati dostignuća studenta.

Proširena realnost, koja omogućava povezivanje digitalnih i fizičkih domena, jedna je od najnovijih tehnologija koja se primenjuje u obrazovanju, time što omogućava da uče efikasnije i prošire svoje znanje u odnosu na tradicionalne 2D desktop interfejse. Proširena realnost podržava razumevanje kompleksnih fenomena pružajući jedinstveno vizuelno i interaktivno iskustvo, koje kombinuje stvarne i virtualne informacije i pomaže $\mathrm{u}$ prenošenju apstraktnih problema učenicima.

Animirani sadržaj koji bi se koristio na predavanjima može privući pažnju učenicima i studentima i motivisati ih da dalje proučavaju. Dodavanjem dodatnih podataka, kao npr. biografija osobe, zabavne činjenice, istorijski podaci o događajima ili lokalitetima, omogućavaju studentima bolje razumevanje teme. AR tehnologija ima sposobnost da predstavi predmete koji se teško mogu zamisliti i pretvoriti u 3D modele.

\section{IZRADA APLIKACIJE ZA EDUKACIJU PROŠIRENU REALNOST}

Praktični deo obuhvata idejno rešenje i proces izrade AR aplikacije za Android platformu. Za kreiranje aplikacije izabrano je Unity softversko okruženje sa Vuforia dodatkom koja se koristi za razvoj AR aplikacija na principu prepoznavanja markera iz realnog okruženja koji aktiviraju digitalni sadržaj koji se prikazuje na ekranu uređaja.

\subsection{Unity}

Unity (Slika) je softversko okruženje za razvoj 3D i 2D video igara za desktop platforme, konzole, mobilne uređaje, kao i za veb dodatke. Unity podržava formate fajlova kao što su .fbx, .dae (Collada), .3ds, .obj, .dxf i .skip fajlove.

Programi za kreiranje 3D objekata iz kojih može biti izvršeno importovanje fajlova su: 3D Studio Max, Maya, Blender, Cinema4D, Modo, LightWave, Cheetah3d. Unity razvojno okruženje nudi aplikacioni programski interfejs (API) u C\# programskom jeziku.

U okviru 2D igre, Unity omogućava uvoz sprajtova i 2D rendera. Za 3D igre, Unity dozvoljava specifikaciju kopresije teksture, mipmapa i podešavaje rezolucije za svaku platformu koju razvojno okruženje za igru podržava. Takođe, pruža podršku za bamp mape, mapiranje refleksije, paralaks mapiranje, ambijentalnu okluziju ekrana, dinamičke senke koje koriste mape senki, efekte pri renderovanju teksture, i drugo [8].

\subsection{Vuforia}

Vuforia je najčešće korišćena platforma za kreiranje AR aplikacija. Vuforiju je osnovala američka kompanija za razvoj i istraživanje bežičnih komunikacija Qualcomm, a 2015. godine je prodata sofverskoj kompaniji PTC.

Ova platforma podržava kreiranje AR aplikacija za Android, iOS i UWP (engl. Universal Windows Platform) uređaje. Sposobnosti prepoznavanja i praćenja mogu se koristiti na različitim slikama i objektima, shodno tome, Vuforija pruža 6 različitih načina za prepoznavanje i praćenje: Model Targets, Image Targets, Object Targets, Multi-Targets, Cylinder Targets, VuMarks, External Camera, Ground Plane [9].

\subsection{Idejno rešenje}

Ideja je da se kreira AR aplikacija za obuku operatera grafičkog sistema Perfecta 76 (Slika 2). 


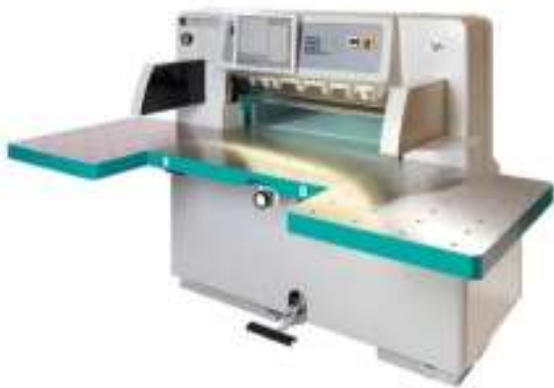

Slika 2. Perfecta 76

Aplikacija sadrži video snimke procesa rezanje naslage materijala, koji su prethodno snimljeni u GRID Grafičkom centru, kao i pojedinačno objašnjenje 12 osnovnih delova mašine: komandni pult (monitor i tasteri), prekidač mašine, prekidač elektromotora, poluga za podešavanje sile pritiska, tasteri za aktiviranje noža, poluga za ručno podešavanje graničnika, nožna poluga, sigurnosne ćelije, ulagajući deo mašine za rezanje, radni sto sa kugličnim ventilima, potpora za poravnavanje naslage materijala.

Pri ulasku u aplikaciju, pojavljuje se glavni meni sa četiri dugmeta: „Specifikacije mašine”, „Video”, „Pokreni AR” i ,O aplikaciji”, (Slika 3).

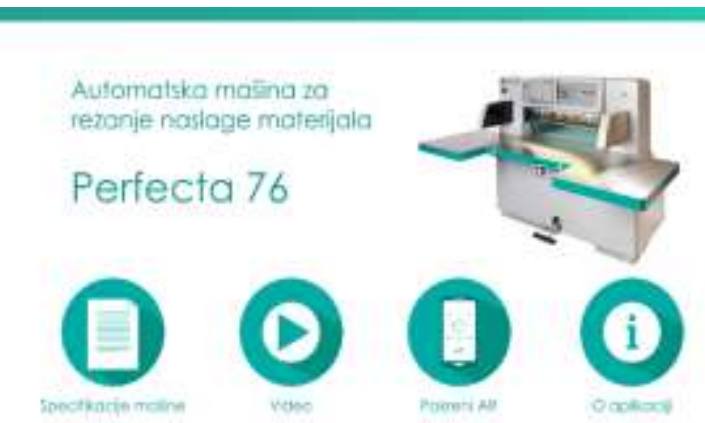

Slika 3. Izgled prozora glavnog menija

Dugme „Specifikacije mašine” sadrži osnovne informacije o mašini kao i tehničke karakteristike mašine.

Dugme ,Video" sadrži video sadržaj procesa rezanja materijala. U okviru ovog prozora nalaze se tri opcije: video prikaz postupka rezanja naslage materijala po koracima, gde je detaljno snimljen svaki korak u postupku rezanja, zatim video prikaz celokupnog postupka rezanja naslage materijala i video prikaz 3D modela mašine.

Dugme „O aplikaciji”, sadrži informacije o verziji aplikacije, autoru i departmanu.

Dugme „Pokreni AR” omogućava pokretanje aplikacije proširene realnosti, tako što se pokreće kamera i korisniku omogućava da na ekranu svog pametnog telefona ili tableta vidi određeni digitalni sadržaj nakon što je marker prepoznat. Za markere postavljene su fotografije delova mašine. Markeri su prikazani na slici 4.

Digitalni sadržaj se prikazuje u vidu prozora koji objašnjava određeni deo mašine. Svaki prozor sadrži naziv tog dela mašine, kratak opis ili uputstvo upotrebe, a za neke je i omogućen dodatni sadržaj u vidu video prikaza i 3D animacije. Primeri nekih od prozora prikazani su na slikama 5, 6 i 7 .

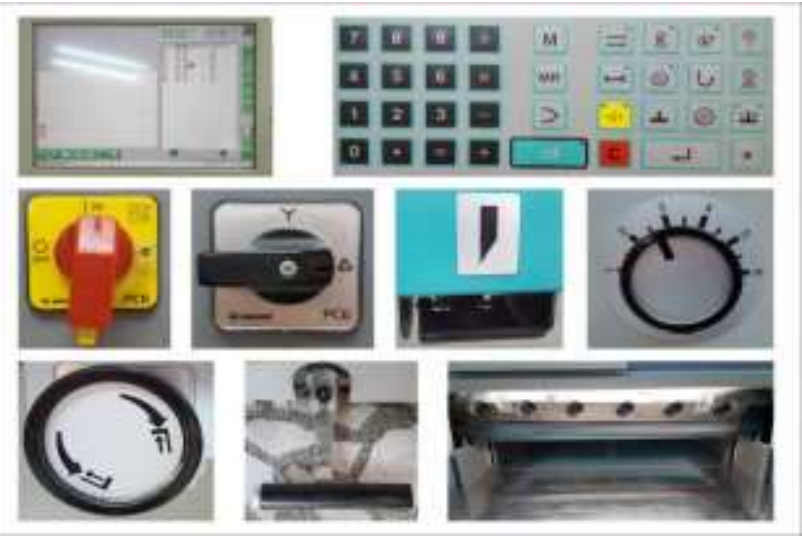

Slika 4. Prikaz markera

Monitor osetijiv na dodir

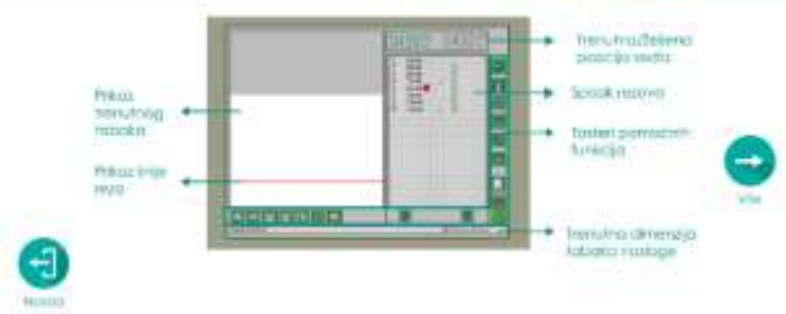

Slika 5. Prikaz prozora „,Monitor osetljiv na dodir“

\section{Tosteri za okfiviranje noża}

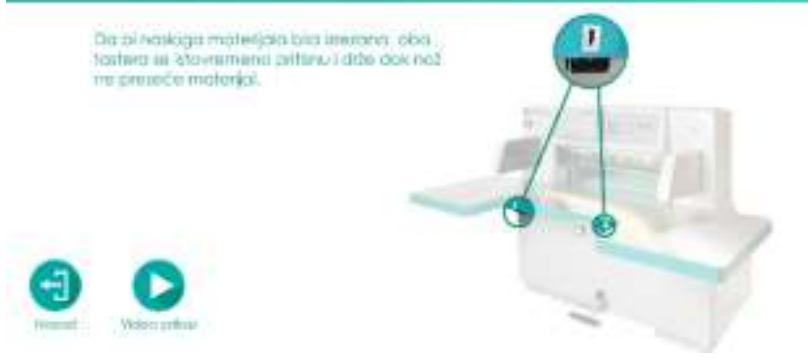

Slika 6. Prikaz prozora „,Tasteri za aktiviranje noža“

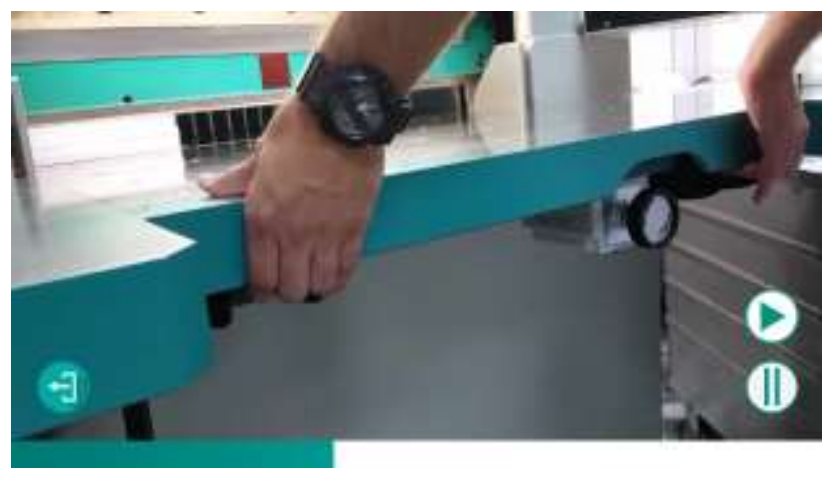

Slika 7. Prikaz video snimka upotrebe tastera za aktiviranje noža

\subsection{Kreiranje instalacione datoteke}

Prilikom kreiranja instalacione datoteke, izabrana je android platforma, dok je za ikonicu postavljen simbol sečenja naslage materijala (Slika 8). Orijentacija je izabrana da bude horizontalno, radi boljeg prikaza sadržaja. 
Kao krajnji rezultat dobija se instalaciona datoteka u .apk formatu.

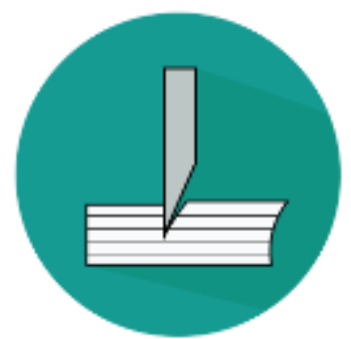

Slika 8. Ikonica aplikacije

\subsection{Testiranje aplikacije}

Aplikacija je testirana na tri Android uređaja: Samsung Galaxy S6, Samsung Galaxy J7 Prime i Huawei P20 lite. Testiranje aplikacije se vršilo pri veštačkom svetlu. Normalna udaljenost pri kojoj je marker prepoznat je oko $30 \mathrm{~cm}$. Nedostaci koji su uočeni pri prepoznavanju markera tiču se autofokusa kamere, zbog čega određeni markeri nisu mogli odmah da budu prepoznati, ali čim se stabilizuje autofokus, markeri su bili prepoznati.

\section{ZAKLJUČAK}

Proširena realnost predstavlja sposobnost za interakciju između fizičkog i virtuelnog sveta u realnom vremenu. Upravo zbog ovih izuzetnih karakteristika očekuje se povećanje obima primene ove tehnologije. Iako nije nova tehnologija usled skorašnjih razvoja u hardverskom i softverskom kapacitetu pametnih telefona, stiče popularnost dan za danom. Tehnologija proširene realnosti nije ograničena samo na industriju zabave, već se koristi od strane mnogih drugih industrija poput medicinske i automobilske industrije, obrazovnih sektora, građevinske industrije, itd.

AR aplikacije mogu da poboljšaju način na koji učimo, time što će učiniti učenje zanimljivijim i prijatnijim. Sistemi proširene realnosti mogu biti korišćeni za reklamiranje istorijskih događaja, za aktiviranje štampanih knjiga u 3D slike ili čak za predstavljanje struktura galaksije, $\mathrm{i}$ to sve pomoću nadograđene grafike u realnom vremenu. Proširena realnost bi bila instrumentalna $\mathrm{u}$ obezbeđivanju praktičnog iskustva za učenike i studente.

Ova aplikacija kreirana je za obuku operatera, gde su kroz video snimke prikazani svi koraci u postupku rezanja naslage materijala, kao i objašnjenja osnovih delova mašine radi lakše upotrebe. Aplikacija je testirana na različitim uređajima, i pored pojedinih nedostataka koji su se javljali pri testiranju, aplikacija je funkcionalna.

\section{LITERATURA}

[1] Historyofinformation, ' Ivan Sutherland and Bob SproullCreate the First Virtual Reality Head Mounted Display System', n.d. [Online]. Dostupno na: http://www.historyofinformation.com/expanded. php?id=1087 , [Pristupljeno: 04.10.2018.]

[2] D.W.F. Krevelen, R. Poelman , "A Survey of Augmented Reality Technologies", The International Journal of Virtual Reality, vol. 9, no. 2, pp. 2, 2010.

[3] R, Azuma, Y. Baillot, R. Behringer, S. Feiner, S. Julier, B. MacIntyre, "Recent advances in augmented Reality", IEEE computer graphics and applications, vol. 3, no. 2, pp.34-47, 2001.

[4] N. Milić, Materijal sa predavanja - Osnove kompjuterskih igara, 2017. [Online]. Dostupno na: http://www.grid.uns.ac.rs/storage/download.php? fajl=1458e 7509aa5f47ecfb92536e7dd1dc7, [Pristupljeno: 12.09.2017.]

[5] Microsoft, What is mixed reality?, 2018. [Online]. Dostupno na: https://docs.microsoft.com/enus/windows/mixed-reality/mixed-reality, [Pristupljeno: 07.10.2018.]

[6] Digit, Welcome to augmented reality, n.d. [Online]. Dostupno na: https://dev.to/theninehertz/what-isaugmented-reality--types-of-ar-and-future-ofaugmented-reality--1en0 , [Pristupljeno: 06.10.2018.]

[7] G. Vladić, D. Novaković, N. Kašiković, I. Pinćer, S. Đurđević, "Transforming product-consumer communication trough augmented reality technology", The 9th International Symposium KOD, Balatonfüred, pp.30., 2016

[8] Unity, Publics Relations, 2018. [Online]. Dostupno na: https://unity3d.com/public-relations , [Pristupljeno: 10.10.2018.]

[9] Vuforia , Vuforia Engine Features, 2018. [Online]. Dostupno na: https://library.vuforia.com/content/ vuforia-library/en/features/overview.html, [Pristupljeno: 13.10.2018.]

\section{Podaci za kontakt:}

\section{Sara Čančarević}

E-mail: 0810sara@gmail.com

\section{dr Gojko Vladić}

E-mail: vladicg@uns.ac.rs 